\title{
Development of High Activity, Coal-Derived, Promoted Catalytic Systems for Nox Reduction at Low Temperatures
}

\author{
Semi-Annual Report \\ October 1, 1997 - March 31, 1998
}

By
J. M. Calo

Work Performed Under Contract No.: DE-FG22-97PC97267

For

U.S. Department of Energy

Office of Fossil Energy

Federal Energy Technology Center

P.O. Box 880

Morgantown, West Virginia 26507-0880

By

Brown University

Chemical Engineering Program

Division of Engineering, Box D

Providence, Rhode Island 02912 


\section{Disclaimer}

This report was prepared as an account of work sponsored by an agency of the United States Government. Neither the United States Government nor any agency thereof, nor any of their employees, makes any warranty, express or implied, or assumes any legal liability or responsibility for the accuracy, completeness, or usefulness of any information, apparatus, product, or process disclosed, or represents that its use would not infringe privately owned rights. Reference herein to any specific commercial product, process, or service by trade

name, trademark, manufacturer, or otherwise does not necessarily constitute or imply its endorsement, recommendation, or favoring by the United States Government or any agency thereof. The views and opinions of authors expressed herein do not necessarily state or reflect those of the United States Government or any agency thereof. 
DEVELOPMENT OF HIGH ACTIVITY, COAL-DERIVED,

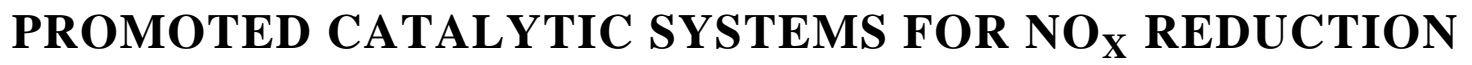
AT LOW TEMPERATURES

Semiannual Technical Progress Report

October 1, 1997 - March 31, 1998

Principal Investigator: J.M. Calo

Submission Date: May 1998

Project Number: DE-FG22-97PC97267 -01

Submitted by:

Brown University

Chemical Engineering Program

Division of Engineering, Box D

Providence, RI 02912

Prepared for:

U.S. DEPARTMENT OF ENERGY

Federal Energy Technology Center (FETC) 


\section{Disclaimer}

This report was prepared as an account of work sponsored by an agency of the United States Government. Neither the United States Government nor any agency thereof, nor any of their employees, makes any warranty, express of implied, or assumes any legal liability or responsibility for the accuracy, completeness, or usefulness of any information, apparatus, product, or process disclosed, or represents that its use would not infringe privately owned rights. Reference herein to any specific commercial product, process, or service by trade name, trademark, manufacturer, or otherwise does not necessarily constitute or imply its endorsement, recommendation, or favoring by the United States Government or any agency thereof. The views

and opinions of authors expressed herein do not necessarily state or reflect those of the United States Government or any agency thereof.

\section{Patent Information}

Yes No

( ) (X) Is any patentable subject matter disclosed in the report?

( ) ( ) If so, has an invention disclosure been submitted to DOE Patent Counsel?

If yes, identify disclosure number or DOE Case Number

Yes No

( ) (X) Are there any patent-related objections to the release of this report? If so, state the objections. 
TABLE OF CONTENTS

EXECUTIVE SUMMARY 1

1.0. PROJECT BACKGROUND AND DESCRIPTION 2

1.1. Background 2

1.2. Scientific Discussion 3

1.3. Project Approach 12

2.0. STATEMENT OF THE PROPOSED WORK 20

LITERATURE REFERENCES 22

3.0. DISCUSSION OF PROGRESS THIS PERIOD 25

4.0. PLANS FOR THE NEXT REPORTING PERIOD 26 


\section{EXECUTIVE SUMMARY}

This project is directed at an investigation of catalytic $\mathrm{NO}_{\mathrm{x}}$ reduction mechanisms on coalderived, activated carbon supports at low temperatures. Promoted carbon systems offer some potentially significant advantages for heterogeneous $\mathrm{NO}_{\mathrm{x}}$ reduction. These include: low cost; high activity at low temperatures, which minimizes carbon loss; oxygen resistance; and a support material which can be engineered with respect to porosity, transport and catalyst dispersion characteristics.

Since the inception of the project, the following has been accomplished:

(1) A MS-TGA (mass spectrometric-thermogravimetric analysis) apparatus, which is one of the primary instruments that will be used in these studies, is being modified to the specific requirements of this project. $\mathrm{A} \mathrm{NO}_{\mathrm{x}}$ chemiluminescence analyzer (ThermoElectron, Model 10) has been added to the instrument to monitor $\mathrm{NO}_{\mathrm{x}}$ concentrations in the feed and product streams. In addition, the computer control and data acquisition system has been updated and modified to accommodate the requirements of the specific types of experiments planned.

(2) Studies of the effects of $\mathrm{NO}$ and $\mathrm{CO}$ in the gas phase on intermediate oxygen surface complex populations on the carbon have also been conducted with phenolic resin char (PRC) in a packed bed reactor. The results suggest that $\mathrm{CO}$ participates in the reduction of NO via reaction with oxygen surface complexes; e.g.,

$$
\begin{gathered}
\mathrm{NO}+\mathrm{C}_{\mathrm{f}} \rightarrow[\mathrm{C}-\mathrm{O}]+1 / 2 \mathrm{~N}_{2} \\
\mathrm{CO}+[\mathrm{C}-\mathrm{O}] \rightarrow \mathrm{CO}_{2}+\mathrm{C}_{\mathrm{f}},
\end{gathered}
$$

where $[\mathrm{C}-\mathrm{O}]$ is an intermediate oxygen surface complex, and $\mathrm{C}_{\mathrm{f}}$ is a free active carbon site. These studies are directed at establishing the mechanisms of gas phase reducing agents on heterogeneous NO reduction.

(3) Work has continued on the application of contrast matching, small angle neutron scattering to the characterization and development of char porosity. Contrast matching with perdeuterated toluene has been used to discriminate between accessible and inaccessible porosity in Pittsburgh \#8 coal char and PRC. This technique is being investigated from the point of view of porosity characterization of the carbon support materials for $\mathrm{NO}_{\mathrm{X}}$ reduction systems.

Plans for the next reporting period include:

- Work on the modification of the MS-TGA apparatus will be completed.

- PRC samples, doped with potassium will be prepared for experimental studies.

- TPR/TPD studies will be initiated to investigate the mechanism of $\mathrm{NO}$ reduction and $\mathrm{N}_{2} \mathrm{O}$ production in the low temperature regime. 


\subsection{PROJECT BACKGROUND AND DESCRIPTION}

\subsection{Background.}

The deleterious environmental consequences of $\mathrm{NO}_{\mathrm{x}}$ emissions are well documented. Their role in the ozone cycle, photochemical smog formation, rain acidification (e.g., see Glassman, 1987), and strong absorption of infrared radiation (i.e., by $\mathrm{N}_{2} \mathrm{O}$; e.g., see Ramanathan et al., 1985; Gallagher, Calo, et al., 1985), have all been well established. For these reasons, $\mathrm{NO}_{\mathrm{x}}$ emissions from fossil fuel sources have become increasingly and more stringently regulated.

Most of the $\mathrm{NO}_{\mathrm{x}}$ that contributes to this problem is released during combustion processes. In recent years, roughly half of the $\mathrm{NO}_{\mathrm{x}}$ emissions originate from automobiles, and the other half from stationary sources (e.g., coal-fired power plants). However, as control of automobile emissions improves, stationary sources will gradually become the major source of $\mathrm{NO}_{\mathrm{x}}$. In stationary combustion systems, $\mathrm{NO}_{\mathrm{x}}$ is generally produced from both nitrogen in the combustion air and from fixed fuel nitrogen. Strategies for reducing $\mathrm{NO}_{\mathrm{x}}$ emissions from these sources focus primarily on control/programming of combustion temperature, oxygen concentration, and fuel nitrogen content. Even so, $\mathrm{NO}_{\mathrm{x}}$ formation is still quite problematic, especially that arising from fuel nitrogen. The primary fuel of interest here is, of course, coal. Coal of all ranks contains roughly $1 \mathrm{wt} \%$ nitrogen, tightly bound in ring structures. Coal combustion converts about $15-40 \%$ of the fuel nitrogen to $\mathrm{NO}_{\mathrm{x}}$, depending on many factors such as the rate and temperature at which fuel species are volatilized (Levy, 1982). For discussions of the relevant mechanisms see, for example, Pohl and Sarofim (1977) and Wójtowicz et al. (1991a,b). Heterogeneous mechanisms via interactions of gaseous nitrogenous species with the solid char matrix contribute significantly to this variability (e.g., see Sarofim and Beér, 1979; Levy, 1982; Wójtowicz et al., 1991a,b; Pels et al., 1993). Indeed, Jüntgen (1987) has noted that that there is no simple relation between coal nitrogen and the net amount of NO formed by combustion. It is also noted that both homogenous gas phase mechanisms and heterogeneous, gas-solid mechanisms have been found to be just as important for both $\mathrm{NO}_{\mathrm{x}}$ formation and destruction.

It is generally agreed that most of the primary $\mathrm{NO}_{\mathrm{x}}$ formed in combustors is $\mathrm{NO}$, rather than $\mathrm{NO}_{2}$ (reported measurements of the latter species can be most often attributed to sampling artifacts; e.g., Johnson et al., 1979). $\mathrm{NH}_{3}$ and $\mathrm{HCN}$ are also formed during coal pyrolysis. In combustors these latter species are usually converted to $\mathrm{NO}_{\mathrm{x}}$; although this is not necessarily so in coal gasifiers. These species can also form $\mathrm{N}_{2} \mathrm{O}$, particularly in fluidized bed combustors (FBC) (Weiss and Craig, 1976; Hao et al., 1987; Gulyurtlu et al., 1994). $\mathrm{N}_{2} \mathrm{O}$ can also be formed and destroyed in heterogeneous processes (Wójtowicz et al., 1991a,b; Pels et al., 1993). $\mathrm{N}_{2} \mathrm{O}$ and $\mathrm{NO}$ concentrations in FBC flue gases have been found to be quite comparable; e.g., $\mathrm{N}_{2} \mathrm{O}$ up to 200 
ppm, and NO up to 1000 ppm (Wójtowicz et al., 1991a,b; Gavin and Dorrington, 1993; Wojtowicz et al., 1994). These studies also conclude that $\mathrm{N}_{2} \mathrm{O} / \mathrm{NO}$ emissions in $\mathrm{FBC}$ are closely coupled, and, therefore, should be considered together in any $\mathrm{FBC} \mathrm{NO}_{\mathrm{x}}$ control strategy.

The practical limitations of all known $\mathrm{NO}_{\mathrm{x}}$ abatement strategies invariably result in the generation of some $\mathrm{NO}_{\mathrm{x}}$ which must then be dealt with by post-conversion treatment processes. This constitutes the principal reason that the Department of Energy has an interest in developing effective approaches to $\mathrm{NO}_{\mathrm{x}}$ treatment, as per the current solicitation for example. In the context of the current proposal, the possibility of addressing this need in a synergistic fashion with another interest of the Department of Energy is emphasized. Namely, in many coal conversion processes, such as mild gasification schemes (Klara and Hand, 1989), solid carbonaceous char byproducts are invariably produced. In addition, and ironically, the increasing implementation of low- $\mathrm{NO}_{\mathrm{X}}$ burners is also producing high-carbon ash which in certain cases is unsuitable for traditional uses, such as concrete manufacture. The economics of such processes can be improved by the utilization of solid carbonaceous products in some "high value-added" manner, rather than simply by combustion or re-burning. The current proposal is specifically directed at investigations of the heterogeneous reduction of $\mathrm{NO}_{\mathrm{X}}$ on promoted carbonaceous supports derived from coal chars in order to develop the basis for economical, effective $\mathrm{NO}_{\mathrm{X}}$ treatment processes.

\subsection{Scientific Discussion}

Although the direct decomposition of NO to its elements is thermodynamically favorable:

$$
\mathrm{NO}(\mathrm{g}) \rightarrow(1 / 2) \mathrm{N}_{2}+(1 / 2) \mathrm{O}_{2} ; \Delta \mathrm{G}_{298}^{\circ}=-20.7 \mathrm{kcal} / \mathrm{mol},
$$

until recently it could not be carried out with any substantial yield, even in the presence of reduced transition metal catalysts. Iwamoto et al. (1986) showed that this reaction occurs appreciably over $\mathrm{Cu}$-exchanged-ZSM-5 zeolite, but the activity of these systems still remains too low to be of commercial significance (Armor, 1992; Regalbuto, 1992).

Currently, indirect decomposition of $\mathrm{NO}$ with reducing agents, such as $\mathrm{NH}_{3}$, urea, or cyanuric acid, to $\mathrm{N}_{2}$ and $\mathrm{H}_{2} \mathrm{O}$, remains the most effective commercial treatment for postcombustion applications. These processes are generally known as selective noncatalytic reduction (SNCR) $\left(900-1100^{\circ} \mathrm{C}\right)$, and selective catalytic reduction (SCR). The latter combines ammonia injection with the use of a solid catalyst (typically $\mathrm{V}_{2} \mathrm{O}_{5}$ and $\mathrm{TiO}_{2}$ ), and is carried out at lower temperatures $\left(300-400^{\circ} \mathrm{C}\right)$. Although effective for $\mathrm{NO}$ removal, these processes can emit excess ammonia to the atmosphere (i.e., "ammonia slip"), and ammonia storage, handling, and transport present problems as well. To circumvent these, urea is often used, especially for small-scale applications. Recently, however, questions concerning the effects of these processes on $\mathrm{N}_{2} \mathrm{O}$ 
emissions have been raised, especially for the higher temperature SNCR processes (Hjalmarrson, 1992; Takeshita et al., 1993).

The fact that the mechanisms of the various heterogeneous reduction systems are still far from completely understood, indicates an opportunity for significant improvement in cost and performance of these systems. A short summary of what is currently known follows.

\subsubsection{Catalytic Reduction/Decomposition of NO on Noncarbonaceous}

Supports. Many potential catalysts for NO reduction have been investigated (e.g., Hightower and Van Leirsburg, 1975). However, typically these systems do not exhibit sustained steady-state activity. Although some noble metals do show considerable initial activity, they are often poisoned by product oxygen; of these, Pt appears to be the most active (Regalbuto, 1992).

As noted, one potentially promising approach is directdecomposition to $\mathrm{N}_{2}$ and $\mathrm{O}_{2}$ on $\mathrm{Cu}$ exchanged ZSM-5 catalyst (Iwamoto et al., 1986; Li and Hall, 1991). Although the catalytic activity of this system is apparently still too low for commercial applications (Li and Armor, 1992), and is susceptible to severe poisoning by sulfur (Regalbuto, 1992), these same catalysts have also been found to be the most active and poisoning resistant for the reduction of $\mathrm{NO}$ with $\mathrm{C}_{2}, \mathrm{C}_{3}$, or higher hydrocarbons in excess oxygen. Along these same lines, it has recently been shown that alkaline earth and transition metal ion-exchanged ZSM-5 zeolites, further exchanged with copper (especially $\mathrm{Mg} / \mathrm{Cu}-\mathrm{ZSM}-5$ ) are active catalysts for $\mathrm{NO}$ reduction in the presence or absence of oxygen, over the temperature range $350-600^{\circ} \mathrm{C}$ (Zhang and Flytzani-Stephanopoulos, 1994). Zeolites are also being investigated for selective catalytic reduction (SCR) of NO with ammonia; in particular, the Fe-Y zeolite system (Amiridis et al., 1993).

1.2.2. The Reduction of NO Over Carbon. NO can be heterogeneously reduced to $\mathrm{N}_{2}$ over carbon, accompanied by the formation of $\mathrm{CO}$ and $\mathrm{CO}_{2}$. This may be represented stoichiometrically as:

$$
\begin{gathered}
\mathrm{C}+2 \mathrm{NO} \rightarrow \mathrm{CO}_{2}+\mathrm{N}_{2} \\
\mathrm{C}+\mathrm{NO} \rightarrow \mathrm{CO}+(1 / 2) \mathrm{N}_{2}
\end{gathered}
$$

In the presence of appreciable $\mathrm{CO}$, the carbon surface-catalyzed reduction of NO, is also known to occur (Chan et al., 1983):

$$
\mathrm{NO}+\mathrm{CO} \rightarrow(1 / 2) \mathrm{N}_{2}+\mathrm{CO}_{2}
$$

Here $\mathrm{CO}$ acts as the reducing agent, and carbon as a catalyst. At lower temperatures NO can be both reversibly and irreversibly chemisorbed on carbonaceous surfaces (Teng and Suuberg, 1993a,b).

In a previous project (UCR grant DE-FG22-87PC79929), we investigated the mechanisms of the uncatalyzed NO-char reaction (Suuberg, Teng, and Calo, 1990; Teng, Suuberg, and Calo, 1992; Teng, 1992). Appreciable NO reduction activity on uncatalyzed carbon systems requires 
relatively high temperatures $\left(>600^{\circ} \mathrm{C}\right)$, and considerable consumption of carbon since the principal reaction products are $\mathrm{N}_{2}$ and $\mathrm{CO}$. Carbon consumption under these conditions is considerably accelerated by the presence of $\mathrm{O}_{2}$ via the carbon-oxygen reaction.

1.2.3. Catalytic NO Reduction on Carbonaceous Supports. The use of low-cost, coal-derived, carbonaceous supports offers some potentially significant advantages for heterogeneous $\mathrm{NO}_{\mathrm{x}}$ reduction systems. These include high activity, as well as a support material which can be engineered with respect to porosity and transport, as well as catalyst dispersion characteristics. Carbonaceous materials are often used as catalysts and catalyst supports (e.g., Jüntgen, 1986). For NO reduction, carbon can act as a reactant, a catalyst, and a support. In order to promote the useful life and activity of such systems, one of the basic objectives is to minimize its role as a reactant, especially in the presence of $\mathrm{O}_{2}$, while maximizing its catalytic properties. Therefore, in order to be practical, the carbon must incorporate a catalyst to reduce the operating temperature and minimize carbon gasification. However, promoted carbon systems that show promise for this application are complex, and thus are still far from being well understood. The elucidation of these mechanisms represents one of the principal thrusts of the current proposal.

Activated carbons (Knoblauch et al., 1981; Mochida et al., 1985; Singoredjo et al., 1991) and soots (Davini, 1988) have also been investigated as catalysts for SCR of NO with ammonia in the presence of oxygen; i.e.,

$$
4 \mathrm{NO}+4 \mathrm{NH}_{3}+\mathrm{O}_{2} \rightarrow 4 \mathrm{~N}_{2}+6 \mathrm{H}_{2} \mathrm{O} \text {. }
$$

Although high activity can be obtained at low temperatures, the addition of ammonia makes it somewhat less attractive than promoted carbons.

Yamashita et al. (1991) reported that the reduction activity of NO over an Australian brown coal char catalyzed by copper, is considerably enhanced in the presence of $\mathrm{O}_{2}$ at low temperatures $\left(\mathrm{ca} .300^{\circ} \mathrm{C}\right)$. Although the temperature range and activity of this system are both promising, the mechanism of this complex reaction system is still not completely understood. At least three interrelated possibilities have been proposed: (1) activation by metallic $\mathrm{Cu}$ oxidation by $\mathrm{O}_{2}$; (2) oxidation of $\mathrm{NO}$ to $\mathrm{NO}_{2}$, which is more reactive towards reduction; and (3) the carbon-oxygen reaction increases the population of surface sites for NO reduction. The role of surface oxygen complexes was further explored by Yamashita et al., (1992), and Yamashita and Tomita, 1993). It was concluded that oxygen surface complexes are important, but it is still not known whether the formation of these species by the carbon-oxygen reaction are $\mathrm{Cu}$-catalyzed, and that they then react directly with $\mathrm{NO}$ (or $\mathrm{NO}_{2}$ ), or whether the $\mathrm{NO}_{\mathrm{x}}$ is reduced directly on the $\mathrm{Cu}$, and the oxidized copper is reduced by carbon. In our own work we have shown that the direct attack of NO on empty, highly reactive, "rapid turnover" sites becomes an important mechanism for the uncatalyzed reduction of $\mathrm{NO}$ on carbon in the high temperature regime $\left(>650^{\circ} \mathrm{C}\right.$ ) (Teng et al., 
1992). It may very well be that the $\mathrm{Cu}$ catalyst plays a role in forming similar sites at lower temperatures.

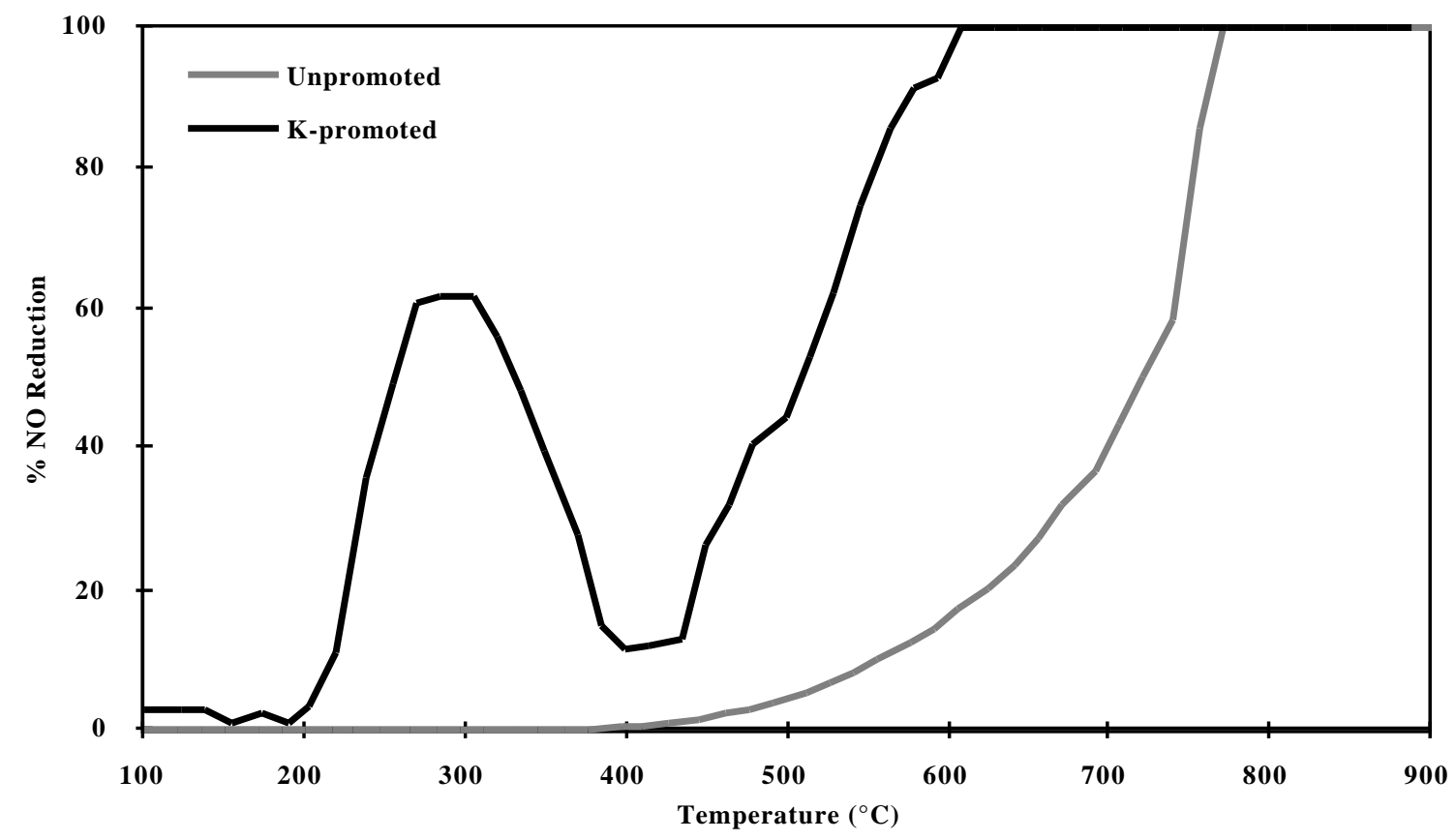

Figure 1. NO TPR profiles for K-promoted and unpromoted samples (Illán-Gómez et al., 1993).

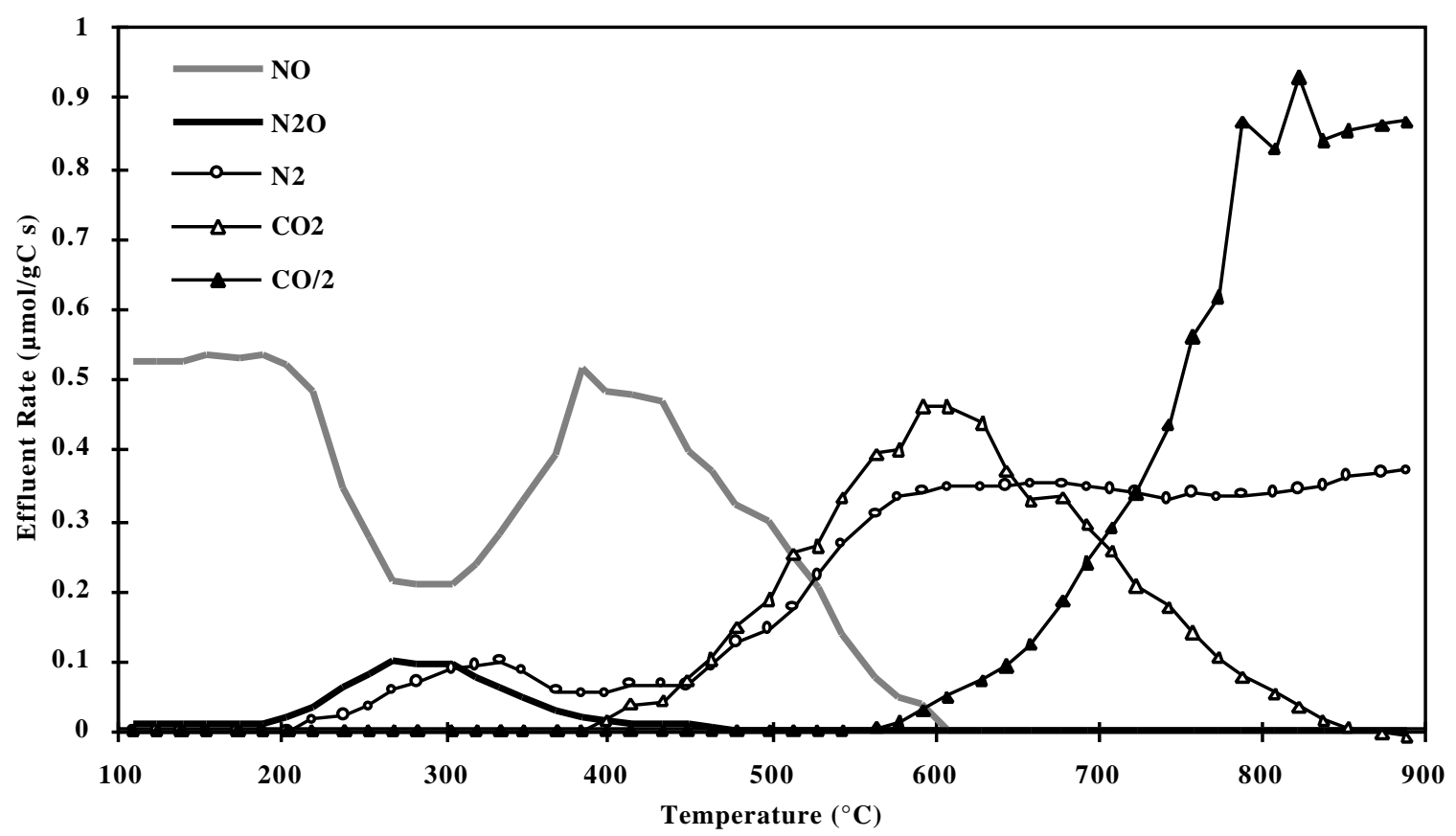

Figure 2.TPR gas composition profiles for K-promoted carbon sample (Illán-Gómez et al., 1993).

A Spanish research group at the University of Alicante, with the participation of the current 
PI, investigated the NO reduction activity of a number of carbons (Illán-Gómez et al., 1993). Some of these were coal chars activated by alkaline hydroxides. Although these latter samples were acid-washed to remove residual alkali metals, it was found that some of the samples behaved quite differently than others in the study. These samples exhibited a marked shift of NO reduction activity to significantly lower temperatures in temperature programmed reaction (TPR) experiments with $0.4 \%$ NO in helium. Moreover, the TPR profiles did not exhibit the "two temperature regime" behavior characteristic of the uncatalyzed NO-carbon reaction (Chan et al., 1983; Teng et al., 1992); but rather a much smoother increase in reactivity with temperature. This behavior was attributed to residual potassium, as revealed by EDAX. Following a second acid-wash, the behavior of these same samples became qualitatively similar to that of all the other uncatalyzed carbons in the study.

In order to explore this behavior further, the least microporous carbon in the study was doped with potassium via ion-exchange with potassium acetate. Figure 1 presents a comparison of the TPR profiles for both the potassium-free and potassium-promoted samples. As shown, the two TPR curves are very different, with the K-promoted sample not exhibiting the characteristic two temperature regime behavior of the uncatalyzed sample. (It is noted that the same qualitative behavior for NO reduction was exhibited by all the uncatalyzed samples in the study.) Potassium considerably enhances both the NO chemisorption and reduction processes, decreasing significantly the threshold temperatures for both processes. In comparison to the TPR profile of the uncatalyzed sample in Figure 1, the onset of NO consumption occurs at about $200^{\circ} \mathrm{C}$. The activity exhibits a maximum at about $300^{\circ} \mathrm{C}$, and thereafter decreases steadily to around $400^{\circ} \mathrm{C}$. Above this temperature, NO reduction increases monotonically again, attaining $100 \%$ reduction at about $600^{\circ} \mathrm{C}$. The corresponding TPR gas composition profiles are presented in Figure 2. Four different regimes of behavior can be discerned in this figure:

Regime \#1: An induction period from room temperature to $200^{\circ} \mathrm{C}$ during which essentially no NO reduction activity is observed. This is attributed to an initial period of diffusional resistance of the entry of NO into the very narrow micropores of this particular sample. This induction period was absent for all the other carbons with wider porosity.

Regime \#2: A period of significant NO uptake from $200-400^{\circ} \mathrm{C}$, with simultaneous formation of $\mathrm{N}_{2}$ and $\mathrm{N}_{2} \mathrm{O} . \mathrm{N}_{2} \mathrm{O}$ appears before $\mathrm{N}_{2}$, and the latter is delayed with respect to NO uptake. As the temperature increases, the formation of $\mathrm{N}_{2} \mathrm{O}$ and $\mathrm{N}_{2}$ both decrease.

Regime \#3: A period of simultaneous evolution of $\mathrm{CO}_{2}$ and $\mathrm{N}_{2}$ begins at $400^{\circ} \mathrm{C}$, with the amount of $\mathrm{CO}_{2}$ exceeding that of $\mathrm{N}_{2}$ up to about $600^{\circ} \mathrm{C}$.

Regime \#4. At temperatures higher than about $600^{\circ} \mathrm{C}, \mathrm{CO}_{2}$ evolution decreases, while that of $\mathrm{N}_{2}$ remains relatively constant. Evolution of $\mathrm{CO}$ appears in this region, and increases continuously 
with temperature, attaining a maximum plateau at about $800^{\circ} \mathrm{C}$.

The TPR gas composition profiles for all the uncatalyzed carbons in the study were qualitatively similar, but differed significantly from that shown in Figure 2. They can be characterized as consisting of Regimes \#3 and \#4 only, with the NO reduction activity shifted to higher temperatures. In particular, no $\mathrm{N}_{2} \mathrm{O}$ evolution (i.e., Regime \#2) was observed for any of the uncatalyzed samples. In fact, literature reports of $\mathrm{N}_{2} \mathrm{O}$ evolution from uncatalyzed carbon systems are rare. In our own study, no $\mathrm{N}_{2} \mathrm{O}$ evolution was observed from the uncatalyzed resin char under all conditions down to $50^{\circ} \mathrm{C}$, although specific efforts were made to search for this product (Teng, 1992). Therefore, it is concluded that partial reduction of $\mathrm{NO}$ to $\mathrm{N}_{2} \mathrm{O}$ on carbons occurs primarily due to the presence of a catalyst, whether present intentionally (i.e., promoted) or unintentionally (i.e., due to mineral matter impurities).

The nitrogen and oxygen balances in Regime \#2 in Figure 2 indicate an accumulation of oxygen on the potassium-promoted carbon during this stage; i.e., the only oxide produced is $\mathrm{N}_{2} \mathrm{O}$. Okuhara and Tanaka (1986) hypothesized that this extra oxygen is transferred to the carbon. However, considering the high reactivity of elemental potassium, the oxygen most probably remains with the potassium, at least initially. The $\mathrm{O} / \mathrm{K}$ ratio is similar to that in $\mathrm{K}$-catalyzed $\mathrm{CO}_{2}$ gasification (Cerfontain et al., 1984). As the temperature increases, $\mathrm{N}_{2}$ is also produced. The increasing oxygen content of the potassium-promoted carbon system is clearly evident in that the rate of $\mathrm{N}_{2}$ formation in this temperature regime is significantly greater than that of $\mathrm{CO}_{2}$.

In Regime \#3 (400-500 ${ }^{\circ} \mathrm{C}$ ), the oxygen-rich potassium transfers oxygen to the carbon surface (undergoing partial reduction), while continuing its catalytic role. In this temperature range, formation of the less stable $\mathrm{CO}_{2}$-producing carbon oxygen complexes is favored, as well as continued reduction of $\mathrm{NO}$ to $\mathrm{N}_{2}$. $\mathrm{CO}$ is not produced in this regime, and gasification is apparently controlled by the slow desorption of oxygen surface complexes (Suuberg, Teng, and Calo, 1990). However, as the temperature increases $\left(\mathrm{T}>600^{\circ} \mathrm{C}\right)$ the $\mathrm{CO}_{2}$ level decreases and the principal products become $\mathrm{CO}$ and $\mathrm{N}_{2}$, perhaps now formed by direct attack and dissociation of the NO molecules at active sites, followed by immediate desorption of the products (Suuberg, Teng, and Calo, 1992).

Since our original work (Illán-Gómez et al., 1993), potassium-promoted carbons have been shown to produce the highest yields of $\mathrm{N}_{2} \mathrm{O}$ in "Regimes \#2 and \#3" at the lowest temperatures of any of the pure metallic redox systems investigated to date (Illán-Gómez et al., 1996).

$\mathrm{Ni}$ - and $\mathrm{Co}-\mathrm{La}_{2} \mathrm{O}_{3}$-Pt dispersed on an activated carbon have also been reported to exhibit high NO reduction activity (Inui et al., 1982), beginning at about $300^{\circ} \mathrm{C}$, with complete conversion by about $400^{\circ} \mathrm{C}$. The behavior of these systems appears to be somewhat similar to the K-promoted system, except that the peak in $\mathrm{N}_{2} \mathrm{O}$ production was shifted to a slightly higher 
temperature $\left(375^{\circ} \mathrm{C}\right)$ and it was coincident with $\mathrm{CO}_{2}$ evolution in the $\sim 300-375^{\circ} \mathrm{C}$ range. In other words, this system does not appear to have separate Regimes \#2 and \#3; they are superimposed. This characteristic could result in a long-lived catalytic system since significant oxygen evolution via $\mathrm{CO}_{2}$ is indicative of continual reduction of the catalyst by carbon. Indeed, in isothermal tests, significant $\mathrm{NO}$ conversion activity was observed for hours. From $440^{\circ} \mathrm{C}$ to $500^{\circ} \mathrm{C}, \mathrm{CO}_{2}$ evolution became constant, following the steady-state stoichiometry:

$$
2 \mathrm{NO}+\text { [promoted } \mathrm{C}] \rightarrow \mathrm{N}_{2}+\mathrm{CO}_{2}
$$

These same composite catalysts (i.e., Ni- and $\mathrm{Co}-\mathrm{La}_{2} \mathrm{O}_{3}-\mathrm{Pt}$ ) dispersed on an activated carbon were also quite effective in the presence of $\mathrm{H}_{2}$ and $\mathrm{CO}$ as reducing agents. Complete reduction of $\mathrm{NO}$ was readily achieved at $180^{\circ} \mathrm{C}$ and $350^{\circ} \mathrm{C}$, with $\mathrm{H}_{2}$ and $\mathrm{CO}$, respectively, without carbon consumption; i.e.,

$$
\begin{aligned}
& \mathrm{NO}+\mathrm{H}_{2} \rightarrow(1 / 2) \mathrm{N}_{2}+\mathrm{H}_{2} \mathrm{O} \\
& \mathrm{NO}+\mathrm{CO} \rightarrow(1 / 2) \mathrm{N}_{2}+\mathrm{CO}_{2}
\end{aligned}
$$

These processes are conceptually similar to SCR, but replace ammonia and related compounds and their problems with $\mathrm{H}_{2}$ and/or $\mathrm{CO}$. The detailed mechanisms of these schemes, however, are still not well understood.

The strong similarities between the latter catalytic system and K-promoted carbons are worth noting. For example, the support for the $\mathrm{Co} / \mathrm{Ni}$-rare earth-Pt systems was a highly activated carbon with a BET surface area of $1230 \mathrm{~m}^{2} / \mathrm{g}$. Of the K-promoted carbon supports in our own work, the most microporous carbon $\left(2087 \mathrm{~m}^{2} / \mathrm{g}\right)$ exhibited the most $\mathrm{N}_{2} \mathrm{O}$ production and the highest specific NO reduction activity; i.e., a coal-derived sample activated in $\mathrm{KOH}$. As noted below in Section 1.2.5, this suggests a role of the nature of the porosity in the effectiveness of the catalyst.

In addition to potential similarities concerning the role of porosity, $\mathrm{CO}_{2}$ evolution begins $c a$. $300^{\circ} \mathrm{C}$ for both systems. In subsequent work (Illán-Gómez et al., 1995b) it was found that the onset of $\mathrm{N}_{2} \mathrm{O}$ production shifted to higher temperatures and came closer to coinciding with $\mathrm{CO}_{2}$ evolution, the higher the K-loading; i.e, Regimes \#2 and \#3 begin to overlap, as observed for the $\mathrm{Co} / \mathrm{Ni}$-rare earth-Pt systems. Also, irrespective of K-loading, 100\% NO reduction, accompanied by constant $\mathrm{CO}_{2}$ and $\mathrm{N}_{2}$ production, was achieved in the $400^{\circ} \mathrm{C}-500^{\circ} \mathrm{C}$ range. The latter characteristic is also the same as exhibited by the $\mathrm{Co} / \mathrm{Ni}$-rare earth oxide-Pt system (Inui et al., 1982). The strong similarities between the two systems suggests that the use of $\mathrm{H}_{2}$ and $\mathrm{CO}$ as reducing agents might be effective for the K-promoted system as well. This approach has the potential of producing a coal-derived, promoted catalytic system, with high activity for $\mathrm{NO}_{\mathrm{x}}$ reduction at relatively low temperatures with no carbon loss.

1.2.4. Heterogeneous Reduction of $\mathrm{N}_{2} \mathrm{O}$. One of the objectives of the current proposal is to establish the basis for the development of a novel, "two-step" process of low 
temperature, quantitative reduction of $\mathrm{NO}$ to $\mathrm{N}_{2} \mathrm{O}$ on a promoted carbon support, followed by complete reduction of $\mathrm{N}_{2} \mathrm{O}$ to $\mathrm{N}_{2}$ and $\mathrm{O}_{2}$ in a second bed of inorganic solids, or perhaps even carbon. While inert at low temperatures, $\mathrm{N}_{2} \mathrm{O}$ readily decomposes to $\mathrm{N}_{2}$ and $\mathrm{O}_{2}$ at higher temperatures, which is the reason that substances which burn briskly in air, actually burn more vigorously in $\mathrm{N}_{2} \mathrm{O}$. It is known that at sufficiently high temperatures, $\mathrm{N}_{2} \mathrm{O}$ decomposes to $\mathrm{N}_{2}$, $\mathrm{CO}$, and $\mathrm{CO}_{2}$ (Wójtowicz et al., 1991a); viz.,

$$
\begin{gathered}
\mathrm{N}_{2} \mathrm{O}+\mathrm{C} \rightarrow \mathrm{N}_{2}+\mathrm{CO} \\
\mathrm{N}_{2} \mathrm{O}+\mathrm{C}(\mathrm{O}) \rightarrow \mathrm{N}_{2}+\mathrm{CO}_{2}
\end{gathered}
$$

where $\mathrm{C}(\mathrm{O})$ is an oxygen surface complex. These same reactions have also been hypothesized to be involved in $\mathrm{N}_{2} \mathrm{O}$ destruction in fluidized bed combustion (FBC).

It is also known that the decomposition of $\mathrm{N}_{2} \mathrm{O}$ to $\mathrm{N}_{2}$ and $\mathrm{O}_{2}$ is well catalyzed by certain inorganic solids in the absence of carbon; viz.,

$$
\mathrm{N}_{2} \mathrm{O} \rightarrow \mathrm{N}_{2}+\mathrm{O}_{2}
$$

In 1929, Shah reported the decomposition of $\mathrm{N}_{2} \mathrm{O}$ over charcoal, silica, platinum foil, platinum black, titania, alumina, and thoria $\left(\mathrm{ThO}_{2}\right)$. All of these catalysts, except for charcoal, which proceeded according to [R.6a,b], were effective for reaction [R.6c] at sufficiently high temperatures. The best performance of all (even better than the charcoal) was exhibited by thoria which was effective at $350^{\circ} \mathrm{C}$, attaining $95 \%$ conversion by $500^{\circ} \mathrm{C}$. Wójtowicz et al. (1991b) investigated the heterogeneous decomposition of $\mathrm{N}_{2} \mathrm{O}$ over various solids and found that alumina was effective, but that Norit RX activated carbon and the same carbon promoted with $\mathrm{CaO}$ were the most effective. However, these workers also noted that there was a strong correlation with BET surface area of the materials investigated, which may imply that $\mathrm{N}_{2} \mathrm{O}$ decomposition occurs primarily via "physical" dissociation. On the other hand, they also noted the strong effect exhibited by $\mathrm{CaO}$ impregnation of the Norit carbon, and thus concluded that "chemical" effects may also be important. It was also demonstrated that $\mathrm{N}_{2} \mathrm{O}$ can be reduced even in the presence of air (Wojtowicz et al., 1991b). Heterogeneous reduction of $\mathrm{N}_{2} \mathrm{O}$ on various inorganic solids (e.g., $\mathrm{CaO}, \mathrm{CaSO}_{4}, \mathrm{MgO}, \mathrm{SiO}_{2}, \mathrm{Fe}_{2} \mathrm{O}_{3}, \mathrm{Fe}_{3} \mathrm{O}_{4}$ ) has also been reported by Miettinen et al. (1991). In particular, oxidation of magnetite $\left(\mathrm{Fe}_{3} \mathrm{O}_{4}\right)$ to hematite $\left(\mathrm{Fe}_{2} \mathrm{O}_{3}\right)$ via reduction of $\mathrm{N}_{2} \mathrm{O}$ was found to be quite effective even at low temperatures $\left(\sim 600^{\circ} \mathrm{C}\right)$.

\subsubsection{The Role of Porosity in NO Reduction on Carbonaceous Supports.}

The role of the nature of the carbon porosity on catalytic NO reduction has only just recently begun to be explored. The principal thesis of our joint work (Illán-Gómez et al., 1993) was the rather surprising observation that for a wide range of carbons (a total of ten), ranging from a pitchbased carbon fiber with an extremely narrow microporosity, to coal chars, all the available surface area (as measured by $\mathrm{N}_{2}$ adsorption) seemed to be effective for $\mathrm{NO}$ reduction; and that accessibility 
problems due to diffusional limitations were not important under the experimental conditions of the study. Even the residual alkali metal-containing coal char samples followed the same trend as all the other carbons in the study after a second acid-wash.

This result is especially interesting in light of our other work on the uncatalyzed NO-char reaction (Suuberg, Teng, and Calo, 1990; Teng, Suuberg, and Calo, 1992; Teng, 1992). One of the conclusions was that "surfaces in the micropores of carbons are not fully utilized," and that "reactive configuration limitations" cause the micropores to be less efficient for NO reduction than for $\mathrm{O}_{2}$ gasification (Teng, 1992). The most significant difference in the experimental conditions between the two studies is the NO level, which was considerably higher (by an order of magnitude) in the latter study than in the former (Illán-Gómez et al., 1993). The higher reactivities, as a result of the higher NO partial pressures used in the former work, could possibly account for the observation of porosity limitations. This is a potentially important issue, since it indicates that the nature of the carbon porosity can affect the activity of the catalytic system, depending on the level of reactivity.

Porosity can also be an important factor for the penetration and efficacy of the catalytic promoter. For example, under certain conditions, promoters such as calcium, introduced via the liquid phase, can be well distributed throughout the entire porosity (Linares-Solano et al., 1989). Introduction as a solid phase, followed by appropriate heat treatment, has been explored for sodium compounds for example (Gómez-Serrano et al., 1993). Since the ultimate catalyst dispersion at reaction conditions is a complex function of many other physicochemical factors as well, it is difficult to isolate the effect of porosity alone (Linares-Solano et al., 1989). However, for reactivity levels where carbon porosity becomes important, it is logical to assume that catalyst dispersion would also be important. Under such conditions, it is possible to engineer the carbon porosity to optimize the activity of the system. Lee et al. (1993) have recently reported that pyrolysis conditions had a significant effect on SCR of NO with ammonia on a lignite char. They ascribed this behavior to the surface area (i.e., porosity) developed during pyrolysis, as well as surface oxygen concentration.

The enhanced adsorptive properties of micropores (pore width $<2 \mathrm{~nm}$ ) in activated carbons offer an interesting, yet complex environment for chemical reactions. In particular, Kaneko and coworkers (1987) have attributed the enhanced micropore filling of NO to its existence primarily in dimeric form within slit-shaped micropores. The high effective pressure/concentration environment of the micropore was investigated for the reaction of dimerized $\mathrm{NO}$ and $\mathrm{NO}_{2}$ with $\mathrm{SO}_{2}$ on an $\alpha$ FeOOH-dispersed activated carbon fiber (Imai et al., 1991). $\mathrm{N}_{2} \mathrm{O}$ was found to be the principal product of the disproportionation of $\mathrm{NO}$ dimer at low temperatures $\left(0-100^{\circ} \mathrm{C}\right)$. Thus, the extent of microporosity can potentially affect reduction activity as well. 


\subsection{Project Approach}

1.3.1. Overview. The reduction of $\mathrm{NO}$ over promoted carbon supports offers potentially significant advantages over all currently known methods. Under proper conditions, these systems exhibit high activity with minimal loss of the carbon support. Moreover, they can be effective at very low temperatures, including the range compatible with post-economizer sections of utility boilers $\left(350-450^{\circ} \mathrm{C}\right.$ ) (Yang and Chen, 1994). However, the fundamental mechanisms of these catalytic systems are still not sufficiently well known to enable the design of an optimal process which exhibits all the desired characteristics. Here it is proposed to focus on a few selected issues of importance in order to improve the current understanding and develop the means to design such systems. Two approaches in particular appear to be particularly attractive and, consequently, will guide the work proposed here: (1) a "two-stage" process involving the quantitative reduction of $\mathrm{NO}$ to $\mathrm{N}_{2} \mathrm{O}$, employing K-promoted or Ni-/Co- $\mathrm{La}_{2} \mathrm{O}_{3}$-Pt-promoted activated carbon, followed by a second step reducing $\mathrm{N}_{2} \mathrm{O}$ to $\mathrm{N}_{2}$ and $\mathrm{O}_{2}$; and (2) reduction of $\mathrm{NO}$ to $\mathrm{N}_{2}$ and $\mathrm{CO}_{2}$ with the same catalytic systems in the presence of the gas phase reducing agents, $\mathrm{H}_{2}$ and $\mathrm{CO}$.

As noted in Section 1.2.3, the partial reduction of $\mathrm{NO}$ to $\mathrm{N}_{2} \mathrm{O}$ is very efficient in "Regimes \#2 and \#3" with potassium, and the combined regimes for $\mathrm{Ni}$ - and $\mathrm{Co}-\mathrm{La}_{2} \mathrm{O}_{3}-\mathrm{Pt}$ dispersed on an activated carbon. Consequently, one approach is to work towards a "two-stage" process of low temperature reduction of $\mathrm{NO}$ to $\mathrm{N}_{2} \mathrm{O}$ on a promoted carbonaceous support, followed by $\mathrm{N}_{2} \mathrm{O}$ reduction to $\mathrm{N}_{2}$ and $\mathrm{O}_{2}$ in another bed of inorganic solid or perhaps even carbon; i.e., complete NO reduction via:

$$
\begin{gathered}
\mathrm{aNO}+\text { [promoted } \mathrm{C}] \rightarrow \mathrm{xN}_{2} \mathrm{O}+\mathrm{yN}_{2}+\mathrm{zCO}_{2} \\
\mathrm{~N}_{2} \mathrm{O} \rightarrow \mathrm{N}_{2}+(1 / 2) \mathrm{O}_{2}
\end{gathered}
$$

This approach has some of the obvious benefits associated with "near-direct reduction" of NO to $\mathrm{N}_{2}$ and $\mathrm{O}_{2}$, as in the zeolite catalyst systems, but with much higher activity, and at a lower cost. In fact, this general strategy of the use of $\mathrm{N}_{2} \mathrm{O}$ as a reducible intermediate has, in a sense, already been proposed in the context of $\mathrm{NO}_{\mathrm{X}}$ abatement in FBC's. That is, intentionally keeping $\mathrm{NO}$ formation low at the expense of high conversion to $\mathrm{N}_{2} \mathrm{O}$, followed by the more facile heterogeneous reduction of $\mathrm{N}_{2} \mathrm{O}$ (Wójtowicz et al., 1991a). However, it is proposed here for the first time as a separate post-combustion, promoted carbon system.

The steady-state carbon loss rate, $\mathrm{C}: \mathrm{NO}$, in [R.10a] can be as low as 1:4, depending on the amount of $\mathrm{N}_{2}$ formed. For example, for the characteristic ratio $\mathrm{N}_{2} \mathrm{O}: \mathrm{N}_{2} \sim 1: 1$, the corresponding overall carbon loss rate would be $\mathrm{C}: \mathrm{NO}=3: 8$. This is considerably better than for noncatalytic reduction to $\mathrm{CO}$ over carbon at higher temperatures $\left(>650^{\circ} \mathrm{C}\right)$; i.e.,

$$
2 \mathrm{NO}+2[\mathrm{C}] \rightarrow \mathrm{N}_{2}+2 \mathrm{CO} \text {. }
$$

for which $\mathrm{C}: \mathrm{NO}$ is $1: 1$. In addition, the process [R.10a,b] completely avoids the formation of CO. 
In order to maximize the production of $\mathrm{N}_{2} \mathrm{O}$, however, it may be more desirable to operate at lower temperatures in "Regime 2" with potassium. Even though $\mathrm{NO}$ reduction and $\mathrm{N}_{2} \mathrm{O}$ production can both be greater in this regime, this occurs along with an accumulation of surface oxygen, most probably on the catalyst. It is currently thought that in order to maintain catalytic activity, oxygen must be continually transferred from the catalytic sites to the carbon. However, it has been demonstrated that steady-state reduction of $\mathrm{NO}$ to $\mathrm{N}_{2} \mathrm{O}$ can be maintained over several hours with a K-promoted activated carbon operating at $300^{\circ} \mathrm{C}$, with the relative abundance of the product gases being $\mathrm{N}_{2} \mathrm{O}>\mathrm{CO}_{2}>\mathrm{N}_{2}$ (Kapteijn et al., 1984). Thus, apparently, the amount of $\mathrm{CO}_{2}$ production (i.e., carbon consumption) necessary to maintain the catalytic reduction of $\mathrm{NO}$ to $\mathrm{N}_{2} \mathrm{O}$ can be kept quite low. Obviously, the production of $\mathrm{CO}_{2}$ minimizes carbon consumption in comparison to the production of $\mathrm{CO}$; and, as clearly shown in Figure 2, no $\mathrm{CO}$ is produced until much higher temperatures in "Regime \#4" $\left(\mathrm{T}>600^{\circ} \mathrm{C}\right)$.

From the available data, it appears that catalytically promoted carbons can produce $\mathrm{N}_{2} \mathrm{O}$ at low temperatures and high rates for sustained periods. However, as in all catalytic systems, activity will eventually decrease with time-on-stream due to catalyst deactivation. For the current systems, this loss in activity is primarily due to the accumulation of oxygen on the metal catalyst. However, a number of well-known options are available to maintain catalytic activity at optimal levels. In a packed bed, activity can be maintained until "breakthrough" occurs. In this case, a system of "swing" packed bed reactors can be used where the gas flow is switched from the deactivated catalyst bed to a regenerated bed. The deactivated bed is then regenerated by reduction of the catalyst. In fluidized bed systems, a portion of the promoted carbon catalyst can be continually withdrawn from the reactor to a regenerator, while activated catalyst is fed continuously back to the reactor pneumatically using pressure differences, as in fluidized bed catalytic cracking for example. Regeneration of the oxidized catalyst in these systems would be rapid, since it simply involves thermal activation in an inert gas.

Another potentially attractive approach which circumvents the use of $\mathrm{N}_{2} \mathrm{O}$ as an intermediate, and does not consume carbon, is the use of promoted carbon catalyst systems employing $\mathrm{H}_{2}$ and $\mathrm{CO}$ as reducing agents, according to reactions [R.7] and [R.8], as discussed above in Section 1.3. This was demonstrated experimentally by Inui et al. (1982) with $\mathrm{Ni}$ - and $\mathrm{Co}_{-}-\mathrm{La}_{2} \mathrm{O}_{3}-\mathrm{Pt}$ dispersed on carbon. The strong similarities between these catalytic systems and K-promoted systems suggests that similar behavior may also be observed with the latter system. However, the detailed mechanisms of these schemes are not well understood, and the optimal conditions (e.g., temperature, partial pressures of the gas phase reducing agents, etc.) have yet to be investigated systematically.

1.3.2. The Effect of Pressure. Although overall NO reduction (e.g. [R.1] is not a 
function of pressure, the mechanistic steps involving $\mathrm{NO}$ chemisorption and $\mathrm{N}_{2} \mathrm{O}$ production are. For example, Okuhara and Tanaka (1986) proposed the following as the mechanism for NO reduction over a K-promoted, mesoporous carbon at temperatures from ambient to $280^{\circ} \mathrm{C}$ :

$$
\begin{gathered}
2 \mathrm{NO} \rightarrow \mathrm{N}_{2} \mathrm{O}+\mathrm{O}(\mathrm{ad}) \\
\mathrm{NO}(\mathrm{ad})+\mathrm{NO} \rightarrow \mathrm{N}_{2} \mathrm{O}+\mathrm{O}(\mathrm{ad})
\end{gathered}
$$

Illán-Gómez et al. (1995b) suggested that NO chemisorption occurs via:

$$
2 \mathrm{NO}+2 \mathrm{~S} \rightarrow 2 \mathrm{~S}(\mathrm{NO}) \rightarrow \mathrm{S}(\mathrm{O})+\mathrm{S}+\mathrm{N}_{2}
$$

The stoichiometry of these systems clearly indicate that increasing NO pressure will favor the formation of $\mathrm{N}_{2} \mathrm{O}$ at the same temperatures. In addition, the reduction reactions with $\mathrm{H}_{2}$ and $\mathrm{CO}$ (i.e., [R.7] and [R.8]) also benefit from increased pressure. However, all the kinetic studies cited here have been conducted at atmospheric pressure. Although there have been some studies on the effects of pressure on the adsorption of NO on unpromoted, activated carbons (Rubel and Stencel, 1996), there have been no systematic studies on the effect of pressure on the reduction of $\mathrm{NO}$ nor on the formation of $\mathrm{N}_{2} \mathrm{O}$ in promoted carbon catalytic systems.

The TGA apparatus which will be used in the current work is capable of operation at elevated pressures. This will enable the systematic investigation of the effects of $\mathrm{NO}$ and $\mathrm{O}_{2}$ (see below) pressures on these systems for the first time.

1.3.3. The Effect of Oxygen. The reduction of $\mathrm{NO}$ and the formation of $\mathrm{N}_{2} \mathrm{O}$ in promoted carbonaceous systems has been generally attributed to redox cycles involving the metal/carbon system. That is, it is believed that NO oxidizes reduced metallic sites, most probably by dissociative chemisorption. The resultant metal oxides are subsequently reduced by carbon via the transfer of oxygen to carbon sites and then, depending on the temperature regime, desorb as $\mathrm{CO}_{2}$ or $\mathrm{CO}$, thereby consuming carbon. Oxygen can compete with $\mathrm{NO}$ for metallic and carbon sites. However, Inui et al. (1982) demonstrated that the Ni-/Co-rare earth-Pt system can completely reduce NO even in the presence of $2 \%$ oxygen. Similar data is not yet available for the K-promoted system. Therefore, a detailed investigation of the competitive effect of oxygen on catalyst oxidation represents an important aspect of the current proposed work for both catalytic systems.

Oxidation of active carbon sites tends to slow down the oxygen transport step. However, the desorption of the surface oxides as $\mathrm{CO}_{2}$ (or $\mathrm{CO}$ ) forms highly reactive "nascent" sites which can be highly effective for reducing the catalyst and transporting oxygen from the metal oxides (e.g., see Yamashita et al., 1991, 1992, 1993). Thus overall, oxygen typically plays a positive role in NO reduction in these systems.

This qualitative picture indicates that in addition to the state of the catalyst, one of the more 
important issues in the overall mechanism is the nature of the carbon active sites involved in the oxygen transfer process -- their chemical nature, their energetics, etc. However, virtually nothing is known about them, other than the hypothesis that they are most probably the ones concentrated at the catalyst-carbon interface (Illán-Gómez et al., 1996); which argues for achieving and maintaining high catalyst dispersion. Since in "Regime \#3," $\mathrm{CO}_{2}$ is the major desorbing oxide of carbon, the oxidized catalyst must form some type of carbo-peroxide complex that decomposes to $\mathrm{CO}_{2}$. Understanding the nature of these special complexes and their energetics would provide considerable insight concerning the critical oxygen transfer process, and consequently the design of an optimum promoted carbon catalyst system.

1.3.4. Temperature Programmed Reaction (TPR). TPR is one of the techniques that will be used to investigate $\mathrm{NO}_{\mathrm{X}}$ reduction mechanisms on the promoted chars. TPR experiments are conducted by varying the system temperature in a programmed fashion (typically linear), in the presence of reactant gases.

For the reaction systems of interest here, the TPR data will be used in two ways. First, these data provide a rapid, consistent method for the determination of absolute and relative activities of different samples and catalyst formulations, as well as the nature of the gaseous products as a function of temperature. This represents a "screening" function. However, the same data can also be analyzed quantitatively to yield global activation energies, as was done in Illán-Gómez et al. (1993), or to deconvolute the kinetics and energetics of the various mechanistic steps involved. An example of what can be done with this approach is provided in a recent paper (Calo et al., 1996) in which TPR (temperature programmed reduction) with hydrogen, and TPD data on the same oxidized samples were used to quantitatively analyze the energetics of the surface complexes and the kinetics of the interaction of hydrogen with oxygen surface complexes. A similar approach will be applied to the NO reduction TPR data.

\subsubsection{Temperature Programmed Desorption (TPD/ITPD). TPD involves the} thermal desorption of adsorbed surface species via a programmed temperature increase (usually a linear ramp) in an inert gas environment. The resultant peaks and their temperatures are related in a fundamental manner to the desorption processes, and, therefore, provide information regarding the energetics of the adsorbed species. The analysis and deconvolution of TPD spectra for energetically homogeneous surfaces is well known. The corresponding situation for energetically heterogeneous surfaces, and for multiple surface species that are very close in energy, such as often occurs for carbons, is more complex. For continuous distributions of surface species, we have developed techniques to transform TPD spectra into probability density functions of desorption activation energies. This approach has been successfully applied to carbon-oxygen surface complexes produced by $\mathrm{CO}_{2}, \mathrm{H}_{2} \mathrm{O}$, and $\mathrm{O}_{2}$ to predict/correlate reactivity, and to 
characterize coal char behavior (Calo and Hall, 1991; Zhang, 1996; Lu, 1996).

We have also used the analysis of TPD data to probe the nature of the relationship between populations of oxygen surface complexes and reactivity in mineral matter-catalyzed steam gasification of coal chars (Calo et al., 1993; Lu, 1996). This work involved the deconvolution of populations of oxygen surface complexes associated with $\mathrm{CaO}$ in the char samples, from those present on carbon active sites. This particular situation is quite similar to that expected for the oxygen surface complexes involved in the catalytic reduction of $\mathrm{NO}$ and $\mathrm{N}_{2} \mathrm{O}$.

TPD techniques have also been used in our laboratory to probe the nature of the uncatalyzed NO-char reaction (Suuberg, Teng, and Calo, 1990; Teng, Suuberg, and Calo, 1992). The desorbed gases are $\mathrm{CO}$ and $\mathrm{CO}_{2}$, which are indicative of oxygen surface complex behavior, and $\mathrm{N}_{2}$ from nitrogen surface complexes. In this particular case we used both post-reaction TPD and a technique whereby we attempted to reconstitute the population of formation rate-controlled oxygen surface complexes (i.e., the lowest desorption energy complexes) that existed in situ at reaction conditions, by cooling the sample in the reaction mixture and "freezing them in" at lower temperatures. In the uncatalyzed NO-char reaction studies these techniques were used to establish the existence of "rapid turnover sites" in the mechanism in the high temperature regime. In addition, isothermal desorption experiments were used to establish that the behavior of the apparent activation energy of the uncatalyzed NO-char reaction, which appears to be directly related to the desorption activation energy distribution for surface oxides (Suuberg, Teng, and Calo, 1990).

For situations intermediate between single energy and continuum descriptions of surface complexes, it is proposed to apply the relatively new technique of intermittenttemperature programmed desorption (ITPD) (Joly et al., 1994). This promises to be a very useful method for the current application, where various, energetically similar, surface species are to be identified. Briefly, the method is as follows. The rate of desorption from a single surface species, $\mathrm{d} \omega / \mathrm{dt}$, in the absence of other effects, is typically well described by a first order process; i.e.,

$$
\mathrm{d} \omega / \mathrm{dt}=\sigma v_{\mathrm{O}} \exp (-\mathrm{E} / \mathrm{RT}),
$$

where $\sigma$ is the concentration of the species in the sample, $v_{\mathrm{O}}$ is the pre-exponential factor, and $\mathrm{E}$ is the activation energy for the desorption of the particular species. The value of $\sigma$ will be approximately constant for a sufficiently small degree of desorption, such that:

$$
\ln [\mathrm{d} \omega / \mathrm{dt}]=\ln \left[\sigma \mathrm{v}_{\mathrm{O}}\right]-\mathrm{E} / \mathrm{RT}
$$

and thus a semilogarithmic plot of gas evolution rate $v s$. 1/T will be linear with a negative slope of -E/R. A sample containing a number of distinct, but closely spaced (in desorption energy) species will yield a corresponding number of different activation energies, if the gas evolution process can be sufficiently well resolved so that the linear relationship in Eq. [2] is maintained. This can be accomplished by using a "sawtooth" heating program which repeatedly sweeps over a particular 
temperature "window", while progressively advancing the "window" in temperature at a lower rate. The effect of this type of program is to "slice-up" the desorption process into finely divided, overlapping "micro-TPD spectra," each of which is sufficiently short to maintain the concentrations of the locally active species approximately constant; i.e., approximating linear behavior as per Eq. [2]. It is noted that this result is not possible with a conventional linear TPD program which "interrogates" all the active species nearly simultaneously and under conditions of continually varying surface concentrations. The resultant semilogarithmic plots of all the "micro-TPD spectra" generated via this method yield "local" desorption activation energies which, when plotted $v s$. the fraction of total gas desorbed, reveal "plateaus" of constant activation energies corresponding to each of the chemically distinct species. We have demonstrated the resolution of three distinct species, very close in desorption activation energies (140, 150 and $160 \mathrm{~kJ} / \mathrm{mole}$ ), and relative abundances of 0.3:1.0:0.4, respectively, using a "sawtooth" heating program with a linear heating rate of $25 \mathrm{~K} / \mathrm{min}$ within each cycle, with a span of $120 \mathrm{~K}$ per cycle, and a cycle-to-cycle displacement of 7K (Calo, 1994). These same species could not be discerned from $a$ conventional $25 \mathrm{~K} / \mathrm{min}$, TPD spectrum.

Both TPD and ITPD methods will be used to investigate the nature of the surface complex intermediates responsible for the catalytic reduction of $\mathrm{NO} / \mathrm{N}_{2} \mathrm{O}$. These species are the direct result of $\mathrm{NO} / \mathrm{N}_{2} \mathrm{O}$ chemisorption and oxygen transfer to active carbon sites. $\mathrm{NO}$, for example, has been shown to be both reversibly (i.e., nondissociatively) and irreversibly (i.e., dissociatively) chemisorbed on carbon (Teng and Suuberg, 1993a,b). In order to be reduced, however, NO must be dissociated. This is one of the primary roles of the catalyst. The efficiency of the oxygen transfer to active carbon sites is then controlled by the ease of reduction of the oxidized catalyst by carbon. Consequently, the proportion of dissociatively vs. nondissociatively chemisorbed NO will then be related to the efficacy of the catalyst. For these reasons, low temperature NO chemisorption on these catalyst systems will also be investigated. Recently, Illán-Gómez et al. (1995b) have correlated low temperature $\left(60^{\circ} \mathrm{C}\right)$ dissociative NO chemisorption to isothermal catalytic activity.

It is also of direct interest to identify whether the sites responsible for $\mathrm{N}_{2} \mathrm{O}$ evolution are the same as for $\mathrm{N}_{2}$ evolution, or whether the difference lies primarily in surface transport of $\mathrm{N}$ atoms. There is also some controversy over whether NO dissociatively chemisorbs to oxygen and nitrogen surface complexes, or whether primarily to just oxygen complexes. Although some evidence of $\mathrm{C}(\mathrm{N})$ species have been reported (Chu and Schmidt, 1993; Suzuki et al., 1994), the prompt generation of $\mathrm{N}_{2}$ and $\mathrm{N}_{2} \mathrm{O}$ during build-up of surface oxygen suggests that oxygen surface complexes are more prevalent than nitrogen complexes.

The catalytic decomposition of $\mathrm{N}_{2} \mathrm{O}$ will be investigated in the same fashion as for $\mathrm{NO}$ using 
TPD and ITPD techniques. That is, the same promoted carbon systems will be examined for $\mathrm{N}_{2} \mathrm{O}$ reduction as well. These data will be useful for both understanding $\mathrm{N}_{2} \mathrm{O}$ reduction over promoted carbon systems, as well as interpreting NO reduction in the presence of $\mathrm{N}_{2} \mathrm{O}$. TPD/ITPD will also be tried on the non-carbonaceous catalytic systems which are of interest for direct reduction of $\mathrm{N}_{2} \mathrm{O}$ to $\mathrm{N}_{2}$ and $\mathrm{O}_{2}$ via [R.10b], although the populations of intermediate surface complexes might be too low to measure very accurately.

\subsubsection{Experimental Systems and Procedures.}

1.3.6-1. HP/HT TGA-MS System for TPR/TPD Studies. The kinetic studies will be conducted primarily in a high pressure/high temperature (HP/HT) TGA system that was recently acquired from DMT of Essen, Germany, with the aid of a DOE University Instrumentation Grant (DE-FG02-95TE00059). This is a versatile microbalance system with a number of important capabilities, including operation up to 100 bar and $1600^{\circ} \mathrm{C}$, simultaneously, with practically any gas mixture, including steam and hydrogen. Although the maximum pressure and temperature operating limits considerably exceed those required for the current studies, operation at elevated pressures is relevant to the proposed work, as discussed above. Four separate flow circuits (three for gases and one for steam), each with its own mass flow controller, can be used to closely control gas mixtures and to perform rapid switching between mixtures. The maximum gas flow rate of $15 \mathrm{slpm}$ (standard liters per minute) ensures differential reactor behavior which is necessary for the TPD/ITPD and TPR experiments. There are two weighing ranges, 0-104 mg and 0-1040 $\mathrm{mg}$ with respective resolutions of $1 \mu \mathrm{g}$ and $10 \mu \mathrm{g}$. Buoyancy corrections are determined and adjusted for flow rate and gas composition automatically with the computer system. The system is operated by a PC with DMT software which is used to monitor, record and display all the data. The control software also allows the programming of practically any heating regimen, as well as any desired variations in the heating program during a run. This feature is ideal for applying the ITPD "sawtooth" heating regimens and "fine-tuning" them during the course of a run.

The DMT HP/HT TGA is interfaced to a UTi 100C quadrupole mass spectrometer. Automated data logging and mass programming is accomplished with a Macintosh IIcx microcomputer with a GW Instruments $625 \mathrm{Jr}$. analog-digital input-output interface. The current control program allows for time-resolved data logging of multiple mass peaks. This system can be used for the proposed work without any major changes, with certain allowances for species detection, as described below.

1.3.6-2. Packed Bed Reactor System. A stainless steel packed bed reactor will be used for isothermal reactivity/catalytic activity studies at pressures identified in the dynamic kinetic studies. As a result of previous work, a programmable mass spectrometer system and temperature programmed furnace are available in our laboratory to operate this packed bed reactor. Thermal 
control of the furnace, mass programming, and data logging are performed with a Macintosh IIcx microcomputer and a GW Instruments MacADIOS $625 \mathrm{Jr}$. interface.

1.3.6-3. Species Detection. Our laboratory is well equipped to detect and measure the various gaseous species of interest. For the proposed work this will be done using a combination of quadrupole mass spectrometry (MS), with $\mathrm{NO}_{\mathrm{x}}$ chemiluminescence analysis, FTIR, or gas chromatography (GC). Due to previous work involving $\mathrm{NO}_{\mathrm{x}}$, we are quite knowledgeable and well-equipped in this regard. In summary, the primary monitoring of the effluent gases from the HP/HT TGA and the packed bed reactor will be done by MS. An auxiliary method will be used to handle the problems of discriminating between $\mathrm{CO}$ and $\mathrm{N}_{2}$, and $\mathrm{CO}_{2}$ and $\mathrm{N}_{2} \mathrm{O}$. FTIR will be tried first; followed by $\mathrm{NO}_{\mathrm{x}}$ chemiluminescence, as appropriate. $\mathrm{GC}$ will be used as an off-line analytical/calibration method or as an on-line method to resolve any problems encountered with the other two methods.

The FTIR spectrophotometer will also be used to investigate the nature of oxygen and nitrogen surface complexes on the promoted carbon systems following chemisorption and isothermalreactivity runs. The FTIR has a thermostatted, diffuse reflectance cell, capable of operation up to $300^{\circ} \mathrm{C}$, which is ideal for the investigation of surface complex types and populations as a function of reaction/chemisorption conditions.

1.3.6-4. Sample Preparation and Characterization Procedures. As a result of previous work, we have acquired considerable experience in preparing and characterizing coal chars. We have the requisite apparatus for pyrolyzing coals under a wide variety of conditions. The resultant chars will be used in their natural (dried) state and also in demineralized form for comparison. It is noted that the demineralization process not only removes mineral matter but also significantly alters the porosity of the resultant char. For some chars demineralization creates larger surface area, and a concomitant increase in surface oxygen for reaction under similar conditions. We will also use char produced by pyrolysis of phenol-formaldehyde resin, synthesized in our laboratory (Suuberg, Wójtowicz, and Calo, 1989), as a "benchmark" carbon support, which is very low in mineral matter impurities.

For the reasons discussed in Section 1.2.3, the proposed work will focus primarily on potassium (Kapteijn et al., 1984; Illán-Gómez et al., 1993), and $\mathrm{Co} / \mathrm{Ni}-\mathrm{La}_{2} \mathrm{O}_{3}-\mathrm{Pt}$ (Inui et al., 1982) - promoted, coal-derived carbons for NO reduction. Since the catalyst preparation procedures are complex, a few different variations must be tried in order to optimize the resultant system as much as possible (e.g., see Linares-Solano et al., 1989, and Gómez-Serrano et al., 1993). Outlines of the initial procedures that will be used follow.

K-promoted samples will be prepared by ion exchange with potassium acetate at a slightly elevated temperature (e.g., $60^{\circ} \mathrm{C}$ ) for a few hours. Catalyst content can be varied by using 
solutions of different concentrations. The carbon samples will then be heat treated in He (e.g., at $950^{\circ} \mathrm{C}$ ) to transform the ion-exchanged potassium species in part to potassium carbonate and potassium oxide, which at temperatures greater than $600^{\circ} \mathrm{C}$ and in presence of carbon, are decomposed and reduced to potassium (Kapteijn et al., 1984). The very active, reduced potassium is transformed to potassium oxide and/or potassium carbonate, depending on experimental conditions. In addition, oxidation of the promoted carbon has also been reported to improve catalyst dispersion (e.g., Linares-Solano et al., 1989), and promote active site formation (Mochida et al., 1985).

For the $\mathrm{Co} / \mathrm{Ni}$ catalyst systems, the carbon samples are first impregnated with the nitrate or chloride salt of the metal at slightly elevated temperature, and then dried. Exposure to an aqueous ammonia solution (10\%) at ambient temperature, followed by heating in nitrogen/10\% hydrogen mixture forms ammonium complexes which are easier to decompose to metallic oxides (Inui et al., 1979, 1982). The oxides are then reduced to the metal at higher temperatures. The other two components ( $\mathrm{La}$ and $\mathrm{Pt}$ ) are then dispersed in the carbon supports from solution at atomic ratios of 0.2 and 0.04 of the substrate, respectively.

The resultant catalyst content of the prepared carbon samples, as well as the original coal chars, will be measured by acid extraction and atomic absorption spectrometry. The dispersion of the catalysts will be examined with X-ray diffraction and with an electron microprobe on an electron microscope available for use in the Division of Engineering of Brown University.

Porosity characterization of the initial and catalyst-loaded carbon supports will be performed with a BET apparatus which is available in our laboratory using $\mathrm{N}_{2}$ and $\mathrm{CO}_{2}$. Since the very smallest pores are not accessible to $\mathrm{N}_{2}$ at $77 \mathrm{~K}$, but are to $\mathrm{CO}_{2}$ at $273 \mathrm{~K}$, the difference in uptake of $\mathrm{N}_{2}$ and $\mathrm{CO}_{2}$ can be used as a simple qualitative indicator of the nature of the porosity (Illán-Gómez et al., 1993).

\subsection{STATEMENT OF THE PROPOSED WORK}

The work will concentrate on elucidating the controlling mechanisms, and obtaining the quantitative data necessary to develop two promising promoted carbon catalytic systems for the reduction of $\mathrm{NO}_{\mathrm{x}}$-- potassium and $\mathrm{Co} / \mathrm{Ni}$-rare earth oxide-Pt on coal-derived carbon supports. In particular, the focus will be on the investigation of : (1) a novel, "two-stage" system for the complete reduction of $\mathrm{NO}$ to $\mathrm{N}_{2}$ and $\mathrm{O}_{2}$ via $\mathrm{N}_{2} \mathrm{O}$ as an intermediate; and (2) the use of $\mathrm{H}_{2}$ and $\mathrm{CO}$ reducing agents in conjunction with the promoted carbon systems. In order to accomplish these objectives the proposed work has been organized into the following tasks:

\section{Sample Preparation and Characterization.}


I.1. Coals obtained from the Argonne Premium Coal Sample Bank, will be used to produce coal-derived supports. Wyodak and Pittsburgh \#8 coals will be tried initially. These two coals have different mineral matter impurities and initial porosity characteristics germane to the current purposes (Calo and Hall, 1991). The resultant coal chars will be activated in steam, $\mathrm{CO}_{2}$, and $\mathrm{KOH}$ solutions. The resultant coal chars will be subjected to catalyst loading in both original and demineralized forms.

I.2. Phenol-formaldehyde resin char will be prepared in a similar manner and used as a non-mineral matter containing "benchmark" char for catalyst loading.

I.3. Char samples will be promoted with appropriate catalysts, as outlined in Section 1.3.64. $\mathrm{K}$ and $\mathrm{Co} / \mathrm{Ni}-\mathrm{La}_{2} \mathrm{O}_{3}$-Pt will be the primary catalytic systems of interest. Variations in catalyst preparation procedures will be pursued in order to optimize the catalytic systems.

I.4. The original and promoted char samples will be characterized with respect to porosity using gas adsorption technique (e.g., $\mathrm{N}_{2}$ and $\mathrm{CO}_{2}$ ); metals content via atomic absorption spectrometry; and catalyst dispersion vis XRD and electron microprobe.

II. NO Reduction.

II.1. TPR studies of NO reduction behavior will be conducted on all the original and promoted char samples in the TGA apparatus presented in Section 3.6-1. Product gas evolution profiles will be used to determine both the reactivity and mechanistic features indicative of the processes occurring on the samples. Particular attention will be focused on the low temperature behavior of these systems; particularly regimes of high $\mathrm{N}_{2} \mathrm{O}$ production in the case of $\mathrm{NO}$ reduction. The effects of the following specific variables on TPR behavior will be examined:

II.1-1. Effects of $\mathrm{NO}, \mathrm{O}_{2}, \mathrm{H}_{2} \mathrm{O}$ and $\mathrm{N}_{2} \mathrm{O}$ concentrations and total system pressure in the HP/HT TGA.

II.1-2. Porosity characteristics of the carbon support will be correlated with reactivity variations with varying $\mathrm{NO}$ partial pressure.

II.1-3. Effects of $\mathrm{CO}$ and $\mathrm{H}_{2}$ reducing agents with respect to concentrations and total pressure in the HP/HT TGA.

II.2. Long-term, isothermal reactivities. Sustained, isothermal reduction activity data will be obtained in packed bed experiments for those catalytic systems which appear to be particularly promising, based upon the TPR studies. These data are necessary to establish the longterm efficacy of the catalyst systems.

II.3. Post-reaction/chemisorption TPD/ITPD spectra will be obtained in the HP/HT TGA. These data will be used to relate the nature and energetics of surface complexes (oxygen and nitrogen), particularly those at the catalyst-carbon interface which are believed to be critical for oxygen transport, to system reactivity and catalyst performance. This information is necessary to 
establish the responsible mechanisms. In those cases, especially at low temperature, involving formation rate-controlled complexes, the technique of "freezing-in" surface populations by cooling in the corresponding gaseous environment, followed by TPD/ITPD, will be used. Of particular interest in these studies is complementary elucidation of the TPR data for the variables listed in Task II.1.

II.4. Post reaction/chemisorption diffuse reflectance FTIR spectra will be obtained, as discussed in Section 3.6-3, in order to aid in the identification of the types of oxygen and nitrogen surface complexes that are active in NO reduction, especially at the catalyst-carbon interface, as a function of catalyst type, reaction/chemisorption conditions, temperature and pressure.

\section{III. $N_{2}$ O Reduction .}

\section{Investigations of $\mathrm{N}_{2} \mathrm{O}$ reduction will be conducted on:}

(1) The same promoted catalytic systems to be explored for NO reduction. These data will be useful for both understanding $\mathrm{N}_{2} \mathrm{O}$ reduction over the promoted carbon systems, as well as interpreting $\mathrm{NO}$ reduction in the presence of $\mathrm{N}_{2} \mathrm{O}$.

(2) Selected noncarbonaceous solids that have been demonstrated to be effective for $\mathrm{N}_{2} \mathrm{O}$ decomposition to $\mathrm{N}_{2}$ and $\mathrm{O}_{2}$; i.e., $\mathrm{Al}_{2} \mathrm{O}_{3}, \mathrm{TiO}_{2}, \mathrm{ThO}_{2}, \mathrm{CaO}$, and $\mathrm{Fe}_{2} \mathrm{O}_{3} / \mathrm{Fe}_{3} \mathrm{O}_{4}$. BET data will be obtained on these solids to investigate correlation with total surface area.

III.1. TPR studies of $\mathbf{N}_{2} \mathrm{O}$ reduction behavior. Product gas evolution profiles will be used to determine both the reactivity and qualitative features indicative of the kinetic processes occurring on the samples. In particular, the effects of the various other gases that may be expected to be present, such as $\mathrm{CO}_{2}, \mathrm{CO}, \mathrm{N}_{2}, \mathrm{O}_{2}$, and $\mathrm{H}_{2} \mathrm{O}$, on system behavior and activity will be explored in limited sets of experiments. Post-TPR, TPD/ITPD studies will be conducted to investigate the nature of the surface complexes that are active in $\mathrm{N}_{2} \mathrm{O}$ reduction, in a manner similar to that described for NO reduction above.

\section{III.2. Isothermal reactivities and post-reaction/chemisorption TPD/ITPD and} FTIR spectra will be obtained following isothermal reaction/chemisorption in a packed bed reactor. The specific systems and types of runs for these studies will be selected based on the results of the TPR studies. These data will be used to relate the type and populations of surface complexes (oxygen and nitrogen) to catalyst system behavior.

\section{LITERATURE REFERENCES}

Amiridis,M.D., F.A.Puglisi, J.A.Dumesic, W.S.Millman, N.-Y. Topsoe, J.Catal. 142,572 (1993).

Armor, J.N., Appl. Catal. B, 1, 221 (1992).

Calo, J.M., and P.J. Hall, ACS Div. Fuel Chem. Prepr. 35(3), 598-605, (1990); Proc. 
Twentieth Biennial Conference on Carbon, UCSB, 1991, p. 496.

Calo, J.M., and P.J. Hall, in Fundamental Issues in the Control of Carbon Gasification Reactivity, J. Lahaye and P. Ehrburger, eds, NATO ASI Series, Series E, 192, p. 329, 1991.

Calo, J.M., W. Lu, L-H Zhang, and J.A. MacKinnon, Proc. Twenty First Biennial Conference on Carbon, SUNY Buffalo, Buffalo, NY, 1993, p. 519.

Calo, J.M., Unpublished Results, 1994.

Calo, J.M., D. Cazorla-Amorós, A. Linares-Solano, M.C. Román-Martínez, and C. SalinasMartínez de Lecea, Carbon, in press, 1996.

Cerfontain, M.B., F. Kapteijn, and J.A. Moulijn,Proc. 8th Int. Conf. on Catal.,Berlin, 1984, p 593.

Chan, L.K., A. Sarofim, and J. M. Beér, Comb. Sci. Technol. 52, 37 (1983).

Chu, X., and L.D. Schmidt, IEC Res. 32, 1359 (1993).

Davini, P., Fuel 67, 24 (1988).

Gallagher, C.C.,C.A. Forsberg, R.V. Pieri, G.A. Faucher, and J.M. Calo, J. Geo. Res.90, 7899 (1985).

Gavin, D.G., and M.A. Dorrington, Fuel 72, 381 (1993).

Glassman, I., Combustion, 2nd ed., Ch. 8, Academic Press, NY, 1987.

Gómez-Serrano, V., F. Sánchez-Iñiguez, A. Bernalte-Garcia, and C. Valenzuela-Calahorro, Fuel 69, 391 (1993).

Gregg, S.J.; Sing K.S.W. AdsorptionSurface Area and Porosity, 2nd ed.; Academic, London, 1982.

Gulyurtlu, I., H. Espareteoro, and I. Cabrita Fuel 73, 985 (1994).

Hao, W.M., S.C. Wofsy, M.B. McElroy, J.M. Beér, and M.A. Toqan, J.Geo.Res. 92, 3098 (1987).

Hightower, J.W., and D.A. Van Leirsburg, in Catalytic Chemistry of Nitrogen Oxides, R.L. Klimsh and J.G. Larson, eds., Plenum Press, London, 1975, p. 63.

Hjalmarsson, A.-K. Interactions in Emissions Control for Coal-Fired Plants IEACR, London, 1992.

Illán-Gómez, M.J., A Linares-Solano, and C. Salinas-Martínez de Lecea, and J.M. Calo, Energy \& Fuels, 7, 146, 1993.

Illán-Gómez, M.J., A Linares-Solano, L.R. Radovic, and C. Salinas-Martínez de Lecea, Energy \& Fuels, 9, 97, 1995a; 9, 104 (1995b); 10, 158 (1996).

Imai, J., M. Souma, S. Ozeki, T. Suzuki, and K. Kaneko, J. Phys. Chem. 95, 9955 (1991).

Inui, T.,K. Ueno, M.Funabiki,M.Suehiro,T.Sezume,Y.J.Takegami, Far. Trans. 75,1495 (1979).

Inui, T., T. Otowa, and Y, Takegami, Ind. Eng. Chem. Prod. Res. Dev. 21, 56 (1982).

Iwamoto, M., H. Furukawa, Y. Mine, F, Uemara, S. Mikuriya, and S. Kagawa, J. Chem. Soc. Chem. Comm., 1272, 1986.

Johnson, G.M., Smith, M.Y., and Mulcahy, M.F.R. Proc. 17th Symp.(Int.) Comb., The Combustion Institute, Pittsburgh, PA, 1979, p. 647.

Joly, J.P., S. Haydar, A. Perrard, C.Moreno-Castilla, J. Rivera-Utrilla, and M.A. Ferro-Garcia, Proc. Carbon '94, Granada, Spain, July, 1994, p. 346.

Jüntgen, H., Fuel 65, 1436 (1986).

Jüntgen, H., Erdol und Kohle - Erdgas - Petrochemie, Brennstoff-Chemie 40, 204 (1987).

Kaneko, K., Langmuir 3, 357 (1987).

Kaneko, K., N. Fukuzaki, and S. Ozeki, J. Chem. Phys. 87, 776 (1987).

Kapteijn, F., A.J.C. Mierop, G. Abbel, and J.A. Moulijn, Proc. Carbone 84, France, 1984, p.60; JACS Comm.1085 (1984). 
Klara, J., and T.J. Hand "Mild Gasification: A New Coal Option," presented at Alternate Energy '89, Tucson, April, 1989.

Knoblauch, K., E. Richter, and H. Jüntgen, Fuel 60, 832 (1981).

Lee, J.K., D.J. Suh, S. Park, and D. Park, Fuel 72, 935 (1993).

Levy, A. Proc. 19th Symp. (Int.) Comb., Combustion Institute, Pittsburgh, PA, 1982, p. 1223.

Li, Y., and J. Armor, Appl. Catal. 76, L1-9, 1991.

Li, Y. and Hall, J., J. Catal. 129, 202 (1991).

Linares-Solano, A., M. Almela-Alarcón, C. Salinas-Martínez de Lecea, D. Cazorla-Amóros, ACS Div. Fuel Chem. Prepr. 34, 136 (1989).

Lu. W., Ph.D. Dissertation, Division of Engineering, Brown University, 1996.

Miettinen, H., D. Strömberg, and O. Lindquist, 11th Int. Conf. FBC, ASME,NY, 1991, 999.

Mochida, I., M. Ogaki, H. Fujitsu, Y. Komatsubara, and S. Ida, Fuel 64, 1054 (1985).

Okuhara, T., and K. Tanaka, J. Chem. Soc. Faraday Trans. 82, 3657 (1986).

Pels, J.R., Wójtowicz, M.A., and Moulijn, J.A. Fuel 72, 373 (1993).

Pohl, J. and Sarofim, A.F., Proc. 16th Symp. (Int.) Comb., Pittsburgh, PA, 1977, p. 491.

Ramanathan, V., R.J. Cicerone, H.H. Singh, and J.T. Kiel, J. Gephys. Res. 90, 5547 (1985).

Regalbuto,J.R.,"An Analysis of Post-Combustion Catalytic Emissions Treatment,"GRI, Chicago, 1992.

Sarofim, A.F., and Beér, J.M. Proc. 17th Symp. Comb. (Int.), Pittsburgh, PA, 1978, p. 189.

Shah, M.S. J. Chem. Soc. 2661 (1929).

Singoredjo, L., F. Kapteijn, J.A. Moulijn, and J.M. Martín-Martínez, Proc. 20th Biennial Conf. Carbon, UCSB, 1991, p. 78

Stegenga, S., Ph.D. Dissertation, Dept. Chemical Engineering, University of Amsterdam, 1991.

Suuberg, E.M., H. Teng, and J.M. Calo, Proc. 23rd Symp. (Int.) Comb. 1990, p. 1205.

Suzuki, T., T. Kyotani, and A. Tomita, IEC Res. 33, 2 (1994).

Takeshita, M., L.L. Sloss, I.M. Smith, $\mathrm{N}_{2} \mathrm{O}$ Emissions From Coal Use, IEACR, Lndon, 1993

Teng, H., E.M. Suuberg and J.M. Calo, ACS Div. Fuel Chem. Prepr. 35(3), 592 (1990).

Teng, H., E.M. Suuberg and J.M. Calo, Energy \& Fuels, 6, 398 (1992).

Teng, H., Ph.D. Dissertation, Division of Engineering, Brown University, Providence RI, 1992.

Teng, H., and E.M. Suuberg, J. Phys. Chem., 97, 47, (1993a).

Teng, H., and E.M. Suuberg, I\&EC Res., 32, 416, (1993b).

Vorres, K.S., Users Handbook for the Argonne Premium Coal Sample Program, ANL/PCSP93/1, Argonne National Laboratory, October, 1993.

Weiss, R.F., and H. Craig, Geophys. Res. Lett. 3, 751 (1976).

Wójtowicz. M.A., Ph.D. Dissertation, Division of Engineering, Brown University, 1988.

Wójtowicz, M.A., J.A. Oude Lohuis, P.J.J. Tromp, and J.A. Moulijn, Proc. Int. Conf. on FBC, E.J. Anthony Canmet, ed., ASME, Book No. I01312B, 1991a, p. 1013.

Wójtowicz, M.A., J.R. Pels, and J.A. Moulijn, Proc.Int.Conf.Coal Sci., Newcastle, 1991b, p. 452.

Wójtowicz, M.A., J.R. Pels, and J.A. Moulijn Fuel73, 11416 (1994).

Yamashita, H., H. Yamada, and A. Tomita, Appl. Catal. L1, 78 (1991).

Yamashita, H., H. Yamada, T. Kyotani, L.R. Radovic, and A. Tomita, Proc. Carbon '92, Essen, Germany, 1992, p. 293.

Yamashita, H., and A. Tomita Energy \& Fuels 7, 85 (1993).

Zhang, Y., and M. Flytzani-Stephanopoulos, in Environmental Catalysis, J.N. Armor ed., ACS Symp. Series 552, ACS, Washington, D.C., 1994. 


\subsection{DISCUSSION OF PROGRESS THIS PERIOD}

Since the inception of the project, the following has been accomplished:

(1) An MS-TGA (mass spectrometric-thermogravimetric analysis) apparatus, which is one of the primary instruments that will be used in these studies, is being modified to the specific requirements of this project. $\mathrm{A} \mathrm{NO}_{\mathrm{x}}$ chemiluminescence analyzer (ThermoElectron, Model 10) has been added to the instrument to monitor $\mathrm{NO}_{\mathrm{x}}$ concentrations in the feed and product streams. In addition, the computer control and data acquisition system has been updated and modified to accommodate the requirements of the specific types of experiments planned. A new microcomputer (Gateway E-3000) and interface boards have been purchased. The control/data logging software system has been changed over to LabView ${ }^{\mathrm{TM}}$ software. Some of these modifications and updates are still in progress, and should be completed late this spring.

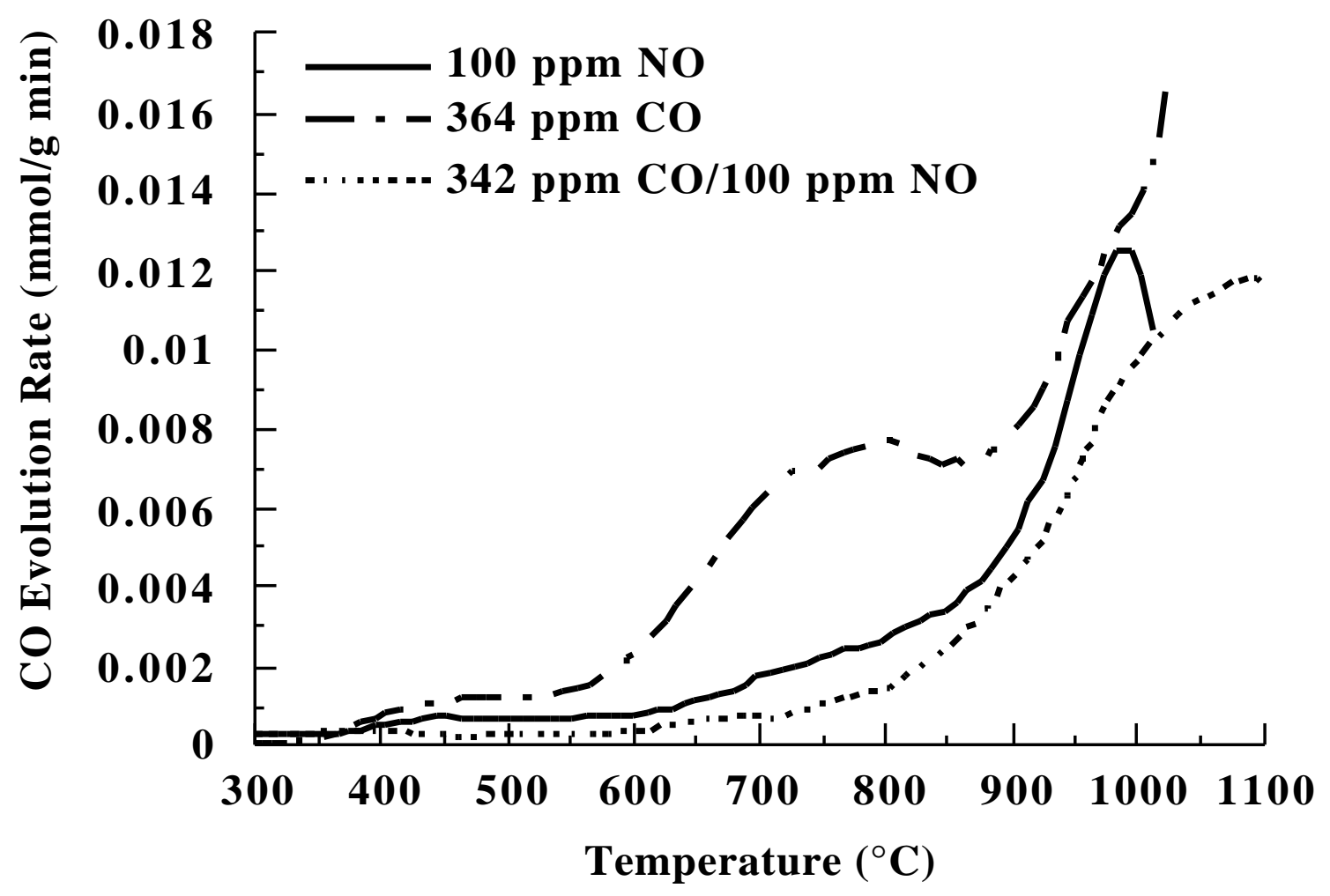

Figure 3. Thermal evolution at $70 \mathrm{~K} / \mathrm{min}$ of surface oxygen (as $\mathrm{CO}$ ) from phenolic resin char oxidized in $\mathrm{NO}, \mathrm{CO}$, and $\mathrm{NO}+\mathrm{CO}$ in a packed bed reactor.

(2) Studies of the effects of $\mathrm{NO}$ and $\mathrm{CO}$ in the gas phase on intermediate oxygen surface complex 
populations on the carbon have also been conducted. Phenolic resin char (PRC) ( $0.25 \mathrm{~g})$ was oxidized in a packed bed reactor ( $4 \mathrm{~mm} \times 2.5 \mathrm{~cm}$ ), with $\mathrm{NO}$ alone, $\mathrm{CO}$ alone, and $\mathrm{NO}+\mathrm{CO}$ in 100 $\mathrm{ml} / \mathrm{min}$ of helium for $2 \mathrm{~h}$ at $800^{\circ} \mathrm{C}$. Samples of this carbon bed material were then subject to temperature programmed desorption in the MS-TGA apparatus at 70K/min in flowing ultrahigh purity helium. Some example results are presented in Figure 3. As shown, with just NO in the flow, relatively little surface oxygen was evolved at temperatures less than $800^{\circ} \mathrm{C}$, with a maximum centered at about $980^{\circ} \mathrm{C}$. With only $\mathrm{CO}$ in the flow, the carbon surface accumulated considerably more oxygen, especially below $800^{\circ} \mathrm{C}$, and no maximum was observed, with $\mathrm{CO}$ evolution still increasing at the maximum temperature. This additional surface oxygen is attributable to direct $\mathrm{CO}$ chemisorption, and perhaps some reverse Boudouard reaction. When both NO and CO were fed together, however, the oxygen surface complex population was observed to decrease to its lowest levels and the maximum in the evolution rate was shifted up to about $1100^{\circ} \mathrm{C}$. These results suggest that $\mathrm{CO}$ participates in the reduction of NO via reaction with oxygen surface complexes; e.g.,

$$
\begin{aligned}
& \mathrm{NO}+\mathrm{C}_{\mathrm{f}} \rightarrow[\mathrm{C}-\mathrm{O}]+1 / 2 \mathrm{~N}_{2} \\
& \mathrm{CO}+[\mathrm{C}-\mathrm{O}] \rightarrow \mathrm{CO}_{2}+\mathrm{C}_{\mathrm{f}},
\end{aligned}
$$

where $[\mathrm{C}-\mathrm{O}]$ is an intermediate surface complex, and $\mathrm{C}_{\mathrm{f}}$ is a free active site. These studies are intended to establish the mechanism of gas phase reducing agents on heterogeneous NO reduction.

(3) Work has continued on the application of contrast matching, small angle neutron scattering to the characterization and development of char porosity. Contrast matching with perdeuterated toluene was used to discriminate between accessible and inaccessible porosity in Pittsburgh \#8 coal char and PRC, for which the mechanisms of porosity evolution were shown to be quite different. Upon progressive activation, Pittsburgh \#8 coal char widens existing porosity and develops new porosity, while PRC progressively opens existing, previously inaccessible porosity via selective burn-off of amorphous carbon which initially blocks the underlying intrinsic porosity. This technique is being investigated from the point of view of porosity characterization of the carbon support materials for $\mathrm{NO}_{\mathrm{x}}$ reduction systems.

\subsection{PLANS FOR THE NEXT REPORTING PERIOD}

The following tasks are planned for the next reporting period:

- Work on the modification of the MS-TGA apparatus will be completed.

- Phenolic resin char samples, doped with potassium will be prepared for experimental studies.

- TPR/TPD studies will be initiated to investigate the mechanism of $\mathrm{NO}$ reduction and $\mathrm{N}_{2} \mathrm{O}$ production in the low temperature regime. 